\title{
Prevalence and Management of Acute Coronary Syndrome with Persistent ST-Segment Elevation in Cardiology Unit of General Hospital of Grand Yoff in Dakar (Experience a Single Center)
}

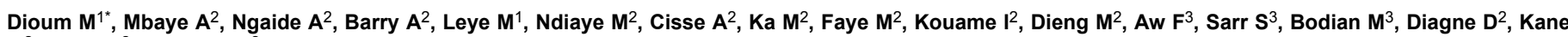
$M^{2}$, Diack $B^{2}$ and Kane $A^{2}$

${ }^{1}$ Faculty of Medicine, Cardiology Clinic of CHU Fann, Cheikh Anta Diop University, Senegal

${ }^{2}$ Faculty of Medicine, General Hospital Cardiology Clinic of Grand Yoff, Cheikh Anta Diop University, Senegal

${ }^{3}$ Cardiology Clinic of CHU Aristide Le Dantec. Faculty of Medicine, Cheikh Anta Diop University, Dakar

*Corresponding author: Dioum M, Cardiology Clinic of CHU Fann, Cheikh Anta Diop University, Hôspital FANN-BP 5534-Dakar- Fann-Senegal, Tel: 221776551883; Email: momar.dioum@yahoo.fr

Received date: October 03, 2016; Accepted date: November 21, 2016; Published date: November 25, 2016

Copyright: (c) 2016 Dioum M, et al. This is an open-access article distributed under the terms of the creative commons attribution license, which permits unrestricted use, distribution, and reproduction in any medium, provided the original author and source are credited.

\begin{abstract}
Introduction: Acute coronary syndromes with persistent ST-segment elevation (STEMI) constitute a cardiologic emergency. The objectives of this study were to investigate their epidemiological, diagnostic, therapeutic, prognostic and evolutionary aspects in cardiologic environment in Dakar.

Patients and methods: It was a retrospective study from January 2013 to December 2014 including patients admitted for STEMI in the cardiology unit of the General Hospital of Grand Yoff. The collected data were analyzed and significance level was selected for a value of $p<0.05$.

Results: We included 114 patients, the prevalence was $10 \%$. The average age was $59.13 \pm 13.7$ years. The sex ratio (M/F) was 1.85 . Cardiovascular risk factors were dominated by sedentary lifestyle $(71.93 \%)$ and arterial hypertension (54.39\%). Chest pain was typical in $69.30 \%$ of cases. The average waiting period for admission was 27.60 hours. Electrocardiographic abnormalities mainly concerned anterior $(62.28 \%)$ and lower $(32.46 \%)$ territories. Thrombolysis was performed in 52 patients $(45.61 \%)$ within an average waiting period of 5.32 hours. Four patients underwent coronary angioplasty. Hemodynamic $(25.39 \%)$ and renal $(12.28 \%)$ complications were more frequent. The hospital mortality rate was $12.28 \%$. Prognostic factors of death were the state of cardiogenic shock $(p=0.001)$ and acute renal failure $(p=0.04)$.
\end{abstract}

Conclusion: STEMI are common in Dakar. Long delays in care and the lack of primary angioplasty are responsible for significant morbidity and mortality.

Keywords: Acute coronary syndrome; Prevalence; Thrombolysis; Senegal

\section{Introduction}

Cardiovascular diseases are the leading cause of morbidity and mortality in Western countries [1]. They are increasing in developing countries, due to the increase of cardiovascular risk factors related to changes of lifestyle in these countries [2].

Coronary diseases are an important part among cardiovascular diseases. They would be according to WHO officials nearly 7 million deaths per year, or $12.8 \%$ of overall mortality in 2012 [1].

Acute coronary syndromes with persistent ST-segment elevation (STEMI), a major cardiac emergency, constitute a public health problem. They require prompt diagnosis and early care $[3,4]$. Primary angioplasty is the ideal treatment of coronary syndromes with persistent ST-segment elevation. Laboratory cardiac catheterization is not available in our hospital. The two interventional cardiologists involved in another hospital for angioplasty. But the majority of patients are treated by thrombolysis.
We conducted this study to assess the prevalence of STEMI, to study their diagnostic, therapeutic and immediate evolutionary aspects and analyze the prognostic factors associated with mortality.

\section{Patients and Methods}

This was a retrospective descriptive study from January 1, 2013 to December 31, 2014 (for a period of 2 years). All patients over 18 years old admitted for STEMI in the cardiology department of the General Hospital of Grand Yoff were included. The diagnosis was based on the presence of two criteria: anginal pain at rest and electrocardiographic changes (at least 2 contiguous leads) with a ST segment elevation of $2 / 10 \mathrm{mV}$ in precordial and $1 / 10 \mathrm{mV}$ in periphery. Studied parameters were the epidemiological data, the mode and delay of admission, the clinical and paraclinical aspects, the care means and the evolution in hospital environment. The data collected from patient records were analyzed using STATA software. The significance threshold was chosen for a value of $\mathrm{p}<0.05$. 
Citation: Dioum M, Mbaye A, Ngaide Aa, Barry A, Leye M, et al. (2016) Prevalence and Management of Acute Coronary Syndrome with Persistent ST-Segment Elevation in Cardiology Unit of General Hospital of Grand Yoff in Dakar (Experience a Single Center). J Cardiovasc Dis Diagn 5: 259. doi:10.4172/2329-9517.1000259

Page 2 of 4

\section{Results}

During the study period, 1141 patients were hospitalized in the cardiology department of the general hospital of Grand Yoff including 114 cases for a STEMI or a hospital prevalence of $10 \%$. The mean age was $59.13 \pm 13.7$ years (18-86 years). The age range (50-69 years) was the most representative (59.65\%). The sex ratio (M/F) was 1.85 . Cardiovascular risk factors were dominated by physical inactivity (71.93\%) and hypertension (54.39\%). Other risk factors were represented respectively by diabetes type 2 (32.46\%), smoking (20.18\%) and dyslipidemia (16.67\%). By doing the accumulation of risk factors, $83 \%$ of patients were multifactorial. The admission average delay after the beginning of pain was 27.60 hours (1-96 hours). Nearly half of the patients $(46.49 \%)$ had arrived in the first twelve hours. A third of the patients $(30.70 \%)$ were presented directly to the home emergency department. The other patients were referred by health facilities $(69.3 \%)$ including twenty-two who had received a pretreatment with aspirin $300 \mathrm{mg}$ orally and seven who had received a pre-treatment with clopidogrel and heparin. Chest pain was typical in $69.30 \%$ of cases. Other signs encountered were vomiting $(28.95 \%)$ and dyspnea (18.42\%). On admission, there was a mean systolic blood pressure of $137.20 \pm 33 \mathrm{~mm} \mathrm{Hg}$, a mean diastolic blood pressure of $86.89 \pm 18.59 \mathrm{mmHg}$ and the mean heart rate was $89.54 \pm 19.60$ beats minute. Twenty-four patients $(21.05 \%)$ had left heart failure and five patients $(4.39 \%)$ were in cardiogenic shock. Electrocardiographic abnormalities were mainly related to anterior territories (62.28\%) and inferior (32.46\%) (Figure 1).

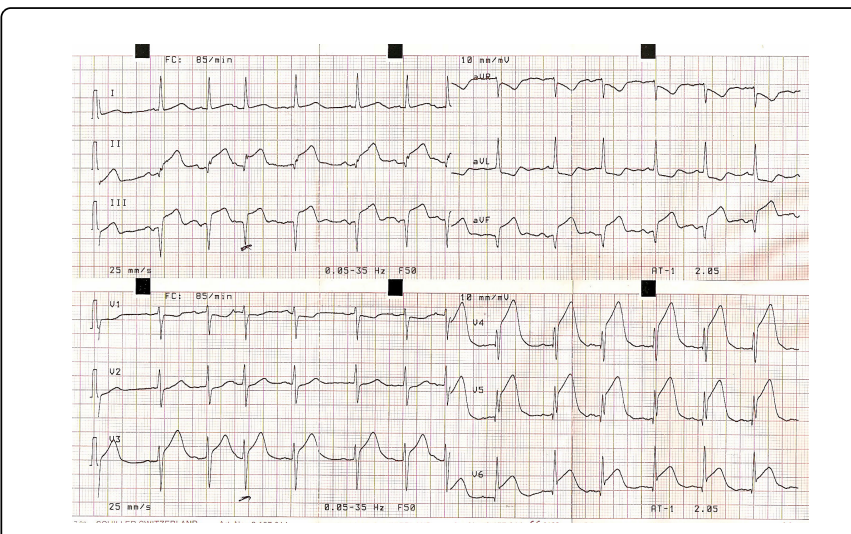

Figure 1: 12-lead electrocardiogram showing a tombstone STelevation in the septal, lateral and inferior leads (DII, DIII, avF) and $\mathrm{Q}$ wave formation.

Nineteen (19) patients (16.67\%) had an extension of infarction to the right ventricle. Two patients had a complete atrio-ventricular block. Troponin assayed in 61 patients $(53.51 \%)$ was positive in all cases with an average rate of $13.45 \mathrm{ng} / \mathrm{L}$. The most frequently met kinetic disorder with Doppler echocardiography was hypokinesia (53\%). The average systolic ejection fraction of LV was $45.11 \%$ (20\% to 83\%). $15.91 \%$ of patients had severely impaired ejection fraction $(\mathrm{LVEF}<30 \%)$. Intramural thrombus was found in $20.18 \%$ of cases (Figure 2).

Thrombolysis was performed in 52 patients (45.61\%) with an average delay of 5.32 hours [1-11 hours]. All patients had received streptokinase at a dose of 1.5 million units' continuous infusion of one hour, preceded by an intravenous bolus of $100 \mathrm{mg}$ of hydrocortisone. Thirty patients $(56.60 \%)$ had a successful thrombolysis with pain relief and regression of ST segment elevation. We noted a failure of thrombolysis of $100 \%$ at $\mathrm{H} 9$ and $70 \%$ at $\mathrm{H} 7$ (Figure 3 ) shows the results of thrombolysis depending on the delay. An allergic reaction to streptokinase was noted in four patients.

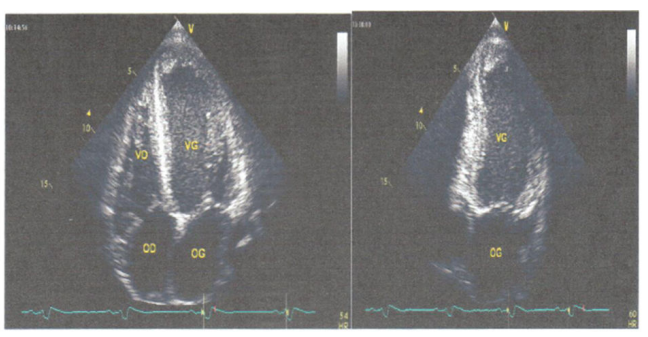

Figure 2: Transthoracic echocardiogram showing an apical thrombus ans spontaneous contrast in the left ventricle.

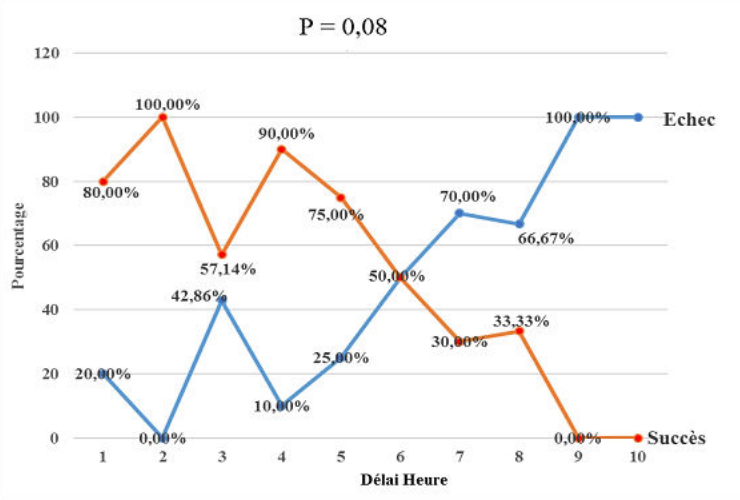

Figure 3: Correlation between results of thrombolysis and treatment delay.

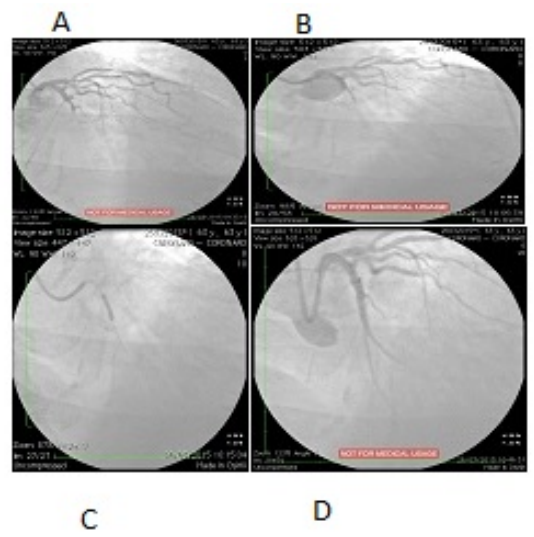

Figure 4: Angioplasty average circumflex in a patient with STEMI lateral.

- A: Occlusion with TIMI flow $\mathrm{O}$ of the circumflex average

- B: Passage of a BMW guidewire 
Citation: Dioum M, Mbaye A, Ngaide Aa, Barry A, Leye M, et al. (2016) Prevalence and Management of Acute Coronary Syndrome with Persistent ST-Segment Elevation in Cardiology Unit of General Hospital of Grand Yoff in Dakar (Experience a Single Center). J Cardiovasc Dis Diagn 5: 259. doi:10.4172/2329-9517.1000259

Page 3 of 4

- C: Setting up an active stent $3^{\star} 18 \mathrm{~mm}$

- D: Good final result with a TIMI flow 3

Hemorrhagic complications were represented by digestive and brain hemorrhages respectively in 4 and 2 patients. Four patients had a delayed coronary angioplasty with placement of bare stent in a patient and drug-eluting stents in three patients (Figure 4).

Two patients had a coronary artery bypass. Medical treatment was initiated in $69.30 \%$ of patients shows the other drugs used (Figure 5). The mean hospital stay was 9.25 days (2-34 days). Hemodynamic $(25.39 \%)$ and renal (12.28\%) complications were more frequent. Hemodynamic complications were dominated by heart failure $(21.05 \%)$ and cardiogenic shock (4.39\%). The hospital mortality rate was $12.28 \%$, including 6 women and 8 men. All patients who died had an age of over fifty years. Prognostic factors of death were cardiogenic shock $(\mathrm{p}=0.001)$ and acute renal failure $(\mathrm{p}=0.04)$.

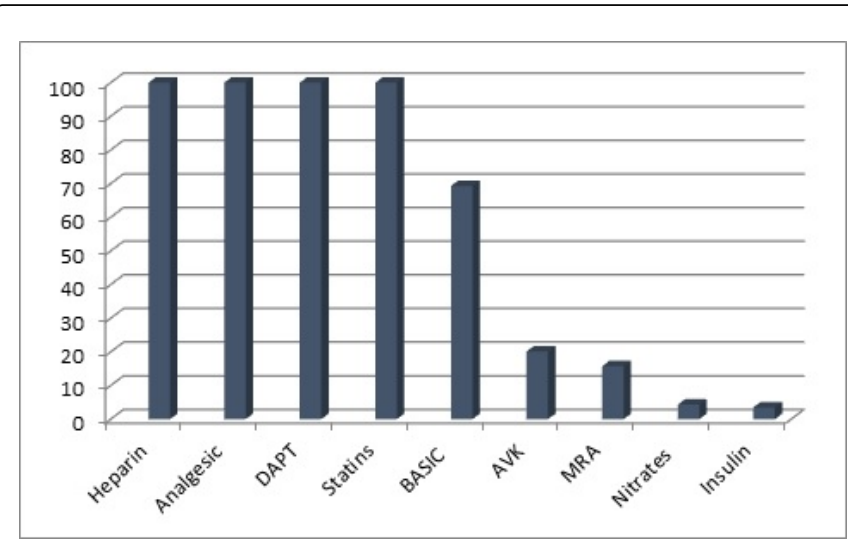

Figure 5: Adjuvant treatment.

- DAPT: Dual anti-platelet therapy

- BASIC: Beta-blocker-anti-platelet therapy-statins-IEC

- AVK: Anti vitamin K

- MRA: Mineralocorticoid receptor antagonist

\section{Discussion}

In our study, the prevalence of acute coronary syndromes was $10 \%$. It was similar to $9.6 \%$ obtained by N'Guetta [5] but lower than that of Damorou which was of 7.3\% [6]. In Africa, there is a steady increase in the prevalence of ischemic heart disease. It was $3.17 \%$ in 1991 in the multicenter prospective study CORONAFRIC I [7]. This prevalence was multiplied by 3 in CORONAFRIC II study. This is explained by the change in the population's lifestyle, the existence of several cardiovascular risk factors and partly by increased screening means. As in other African series, the average age of discovery revolves around fifty with a male predominance $[8,9]$. Our patients were multifactorial. This would confirm the prediction of Koate et al. [10] that in the future, African subjects will be multifactorial. As in other African series, consultation's average delays were long $[11,12]$. This could be explained by the poor pre-hospital management, the atypical clinical presentation and the socioeconomic conditions. Anginal symptoms represented the master symptom compared to the literature [11-13]. The predominance of anterior territory damage confirms the already known data [11]. However, the risk of mortality at one year was multiplied by 1.6 in the case of anterior localization of myocardial infarction [14].

Thrombolysis, effective means of myocardial reperfusion, more available and more accessible than angioplasty in this context was performed in $45.61 \%$ of cases. The implementation of thrombolysis rate is higher in the work performed in England with 70\% [15] and $61 \%$ in Tunisia [16]. Our data significantly lower than indicators observed in European registers can be explained by the extension of admission delay at the emergency departments of hospitals in Dakar [11]. The average admission delay was 27.60 hours in our study. It is due to the ignorance of people regarding coronary artery diseases, the inadequacy or absence of mobile emergency and home intervention teams, but also the cost and availability of thrombolytic. Primary angioplasty is now the reference reperfusion treatment and should therefore be preferred if those deadlines can be met [17]. However, it was not performed in this study due to the absence of interventional cardiology tray available in emergency 24/24. Our patients had a delayed angioplasty. Because of the difficulties linked to the achievement of thrombolysis and primary angioplasty, our patients had mostly received medical treatment (69.3\%). Cardiogenic shock is a common complication of severe myocardial infarction. As in the FAST-MI registry [18], the frequency of cardiogenic shock was $4 \%$ in the general population of MI, similar to the rate found in our study $4.39 \%$. It is a predictor of early and late mortality. In our patients, there was a statistically significant relationship between mortality and cardiogenic shock $(\mathrm{P}=0.001)$. Similarly, kidney failure was an independent risk factor for the occurrence of hospital death in our study $(\mathrm{P}=0.04)$. In developing countries, mortality remains high while Western countries have experienced a significant decrease in mortality in recent years with a mortality rate ranging from $7 \%$ to $10 \%$ according to the literature $[19,20]$. In our study, the hospital mortality observed was $12.28 \%$. Our results were below some data found in the literature: $15.25 \%$ in Mboup's study [11] and 20\% in the study of Maurin et al. [9]. However, Yaméogo [12] had a similar mortality rate (11.6\%). This difference is related to long delays in care and the difficulties associated with thrombolysis and primary angioplasty in our hospitals.

\section{Conclusion}

Acute coronary syndromes with ST-segment elevation are common and on marked growth in Dakar in correlation with increased cardiovascular risk factors. Admission delays are long, often postponing the diagnosis and management. The absence of primary angioplasty and early thrombolysis worsens the prognosis and increases morbidity and mortality.

\section{Note}

All authors participated in the finalization of the document.

\section{References}

1. WHO (2012) The top 10 causes of death.

2. Bertrand E, Muna WFT, Diouf SM, Ekra A, Kane A, et al. (2006) Urgences cardio-vasculaires en Afrique sub saharienne. Arch Mal Coeur Vaiss 99: 1159-1165.

3. Steg PG, James SK, Atar D, Badano LP, Lundqvist CB, et al. (2012) ESC Guidelines for the management of acute myocardial infarction in patients presenting with ST-segment elevation: The Task Force on the management of ST-segment elevation acute myocardial infarction of the European Society of Cardiology (ESC). Eur Heart J 33: 2569-2619. 
Citation: Dioum M, Mbaye A, Ngaide Aa, Barry A, Leye M, et al. (2016) Prevalence and Management of Acute Coronary Syndrome with Persistent ST-Segment Elevation in Cardiology Unit of General Hospital of Grand Yoff in Dakar (Experience a Single Center). J Cardiovasc Dis Diagn 5: 259. doi:10.4172/2329-9517.1000259

Page 4 of 4

4. O'Gara PT, Kushner FG, Ascheim DD, Casey DE, Chung MK, et al. (2013) 2013 ACCF/AHA guideline for the management of ST elevation myocardial infarction: executive summary: A report of the American College of Cardiology Foundation/AHA. Tast Force on practice guidelines. J Am Coll Cardiol 61: 485-510.

5. N'Guetta R, Yao H, Ekou A, N'Cho-Mottoh MP, Angoran I, et al. (2016) Prevalence and characteristics of acute coronary syndromes in a subSaharan African population. Ann Cardiol Angéiol 65: 59-63.

6. Damorou F, Baragou S, Pio M, Afassinou YM, W N'da N, et al. (2014) Morbidity and hospital mortality of cardiovascular diseases in the tropics: example of a hospital in Lomé (Togo). Pan Afr Med J 17: 62.

7. Ticolat P, Bertrand E, Barabe P (1991) Epidemiological aspects of coronary disease in the African Black about 103 cases. Results of the prospective study CORONAFRIC. Cardiol trop 17: 7-20.

8. Kaky KG, Bouramoue C (2000) Profile and future Congolese patients with coronary heart disease about 74 cases. Méd Afr Noire 47: 197-203.

9. Maurin O, Massoure PL, De Regloix S (2012) Myocardial infarction acute in Djibouti: Prospective study over two years. Méd et Santé trop 22 : 297-301.

10. Koate P, Diouf S, Sylla M (1981) Ischemic heart disease in multiple cardiovascular risk factors among the Senegalese. Dakar Méd 26: 377-387.

11. Mboup MC, Diao M, Dia Km, Fall PD (2014) Acute coronary syndromes in Dakar: treatment and outcome clinical aspects. Pan Afr Med J 19: 126.

12. Yaméogo NV, Samadoulougou A, Millogo G, Kologo KJ, Kombassere K, et al. (2012) Support times of acute coronary syndromes STEMI segment in Ouagadougou and factors associated with a lengthening of the time: cross-sectional study about 43 cases collected at CHU-Yalgado Ouédraogo. Pan Afr Med J 13: 90.

13. Thiam M, Cloatre G, Fall F (2000) Ischemic heart diseases in Africa: experience of the Principal Hospital in Dakar. Méd Afr Noire 47: 281-284.

14. Cambou JP, Genes N, Vaur L, Dubroca I, Etienne S, et al. (1998) Epidemiology of myocardial infarction in France: 1 year survival of patients in the study Usik. Arch Mal Cour 91: 1103-1110.

15. Carruthers KF, Dabbous OH, Flathers MD, Starkey I, Jacob A, et al. (2005) Contemporary management of acute coronary syndromes: Does the pratice match the evidence? The global registry of acute coronary events (GRACE). Heart 91: 290-298.

16. Khalfallah AB, Sanaa I, Annabi N, Ousji M, Aloui H, et al. (2005) Predictive value of markers of inflammation in acute coronary syndromes. Arch Mal Cœur Vaiss 98: 899-905.

17. Puymirat E, Ducrocq G (2013) Comparison of European recommendations (ESC) and American (ACC / AHA) regarding the initial management of acute coronary syndromes with ST segment above. Ann Cardiol Angéiol 62: 265-268.

18. Hanssen M, Cottin Y, Khalife K, Hammer L, Goldstein P, et al. (2012) French registry on acute ST-elevation and non ST-elevation myocardial infarction 2010.FAST-MI 2010. Heart 98: 699-705.

19. Danchin N, Puymirat E, Aissaoui N, Adavane S, Durand E (2010) Epidemiology of acute coronary syndromes in France and Europe. Ann Cardiol Angéiol 59: 37-41.

20. Ferrier C, Belle L, Labarene J (2007) Comparison of mortality depending on the revascularization strategy and period pain management of STEMI. Ann Mal Cour Vaiss 1: 13-19. 